\title{
Case Management in Primary Care for Frequent Users of Health Care Services: A Realist Synthesis
}

\author{
Catberine Hudon, MD, PbD \\ Maud-Christine Chouinard, RN, \\ $\mathrm{PbD}$ \\ Kris Aubrey-Bassler, MD, MSc \\ Nazeem Mubajarine, PbD \\ Fred Burge, MD, MSc \\ Paula Louise Bush, PbD \\ Alya Danish, PbD \\ Vivian R. Ramsden, RN, PbD \\ France Légaré, MD, PbD, CFPC \\ Line Guénette, BPharm, $P b D$ \\ Paul Morin, PbD \\ Mireille Lambert, MA \\ Fiona Fick, MA \\ Olivia Cleary, MAPS \\ Véronique Sabourin \\ Mike Warren \\ Pierre Pluye, MD, PbD
}

\section{$\sqrt{m}$ MORE ONLINE \\ www.annfammed.org}

\begin{abstract}
PURPOSE Case management (CM) is a promising intervention for frequent users of health care services. Our research question was how and under what circumstances does CM in primary care work to improve outcomes among frequent users with chronic conditions?
\end{abstract}

METHODS We conducted a realist synthesis, searching MEDLINE, CINAHL, Embase, and PsycINFO (1996 to September 2017) for articles meeting the following criteria: (1) population: adult frequent users with chronic disease, (2) intervention: $\mathrm{CM}$ in a primary care setting with a postintervention evaluation, and (3) primary outcomes: integration of services, health care system use, cost, and patient outcome measures. Academic and gray literature were evaluated for relevance and robustness. Independent reviewers extracted data to identify context, mechanism, and outcome (CMO) configurations. Analysis of CMO configurations allowed for the modification of an initial program theory toward a refined program theory.

RESULTS Of the 9,295 records retrieved, 21 peer-reviewed articles and an additional 89 documents were retained. We evaluated 19 CM interventions and identified $11 \mathrm{CMO}$ configurations. The development of a trusting relationship fostering patient and clinician engagement in the $\mathrm{CM}$ intervention was recurrent in many CMO configurations.

CONCLUSION Our refined program theory proposes that in the context of easy access to an experienced and trusted case manager who provides comprehensive care while maintaining positive interactions with patients, the development of this relationship fosters the engagement of both individuals and yields positive outcomes when the following mechanisms are triggered: patients and clinicians feel supported, respected, accepted, engaged, and committed; and patients feel less anxious, more secure, and empowered to self-manage.

Ann Fam Med 2020;18:218-226. https://doi.org/10.1370/afm.2499.

\section{INTRODUCTION}

$\mathrm{F}$ requent users of health care services are a small proportion of the population who account for a disproportionate number of visits to emergency departments, thereby placing a heavy strain on limited resources. ${ }^{1-3}$ Frequent users generally have complex health care needs, owing to a combination of chronic health conditions, ${ }^{4,5}$ mental health issues, ${ }^{6,7}$ and social vulnerability. ${ }^{8,9}$ These individuals are hospitalized at greater rates than infrequent users, have lower perceived quality of life, ${ }^{10}$ and have a greater mortality rate. ${ }^{8,11,12}$ These complex health care needs make it difficult for the health care system to provide integrated care, highlighting the need for improved management of care for this population.

Case management $(\mathrm{CM})$ is a promising intervention to improve health care integration for frequent users and to reduce health care costs. ${ }^{13-15}$ Case management is defined as "a collaborative process of assessment, planning, facilitation, care coordination, evaluation, and advocacy for options and services to meet an individual's and family's comprehensive health care needs through communication and available resources to pro- 
mote quality, cost-effective outcomes." ${ }^{\prime 16}$ Case management offers support for patients and their families to manage their medical and social issues more effectively and improve their health status and health care use ${ }^{17} ;$ it is designed to enhance care coordination, avoid duplication of services, and reduce health care costs. ${ }^{18}$

The effectiveness of the CM approach for frequent users has been evaluated in many systematic reviews, the majority of which reported positives outcomes such as reduction of health care use and cost and improvement in patient quality of life and satisfaction. ${ }^{13-15,19}$ Case management is a complex social intervention rooted in intricate social systems, all of which influence the outcomes of the intervention. ${ }^{20}$ Whereas quantitative systematic reviews provide evidence for the effectiveness of CM, the causal mechanisms underpinning this intervention, and how contextual factors influence the links between the causal mechanisms and the intervention outcomes, remain unclear. A deeper understanding of how, when, and why CM is successful is needed for its effective implementation in different contexts.

The research question of the present study was how and under what circumstances does CM in primary care work to improve outcomes among frequent users with chronic conditions?

\section{METHODS}

\section{Design}

Realist synthesis (RS) methodology is a theory-driven approach to synthesizing evidence regarding complex social interventions involving a chain of processes, to identify invisible causal mechanisms, examine how they operate under different conditions, and determine how contextual factors influence links between these mechanisms and outcomes. These relations in RS provide a causal explanation for outcomes and are expressed in the form of context + mechanism = outcome (CMO) configurations, a mechanism being the combination of resources offered by the intervention and the way these resources change stakeholders' reasoning. ${ }^{21,22}$ An initial program theory is developed based on assumptions regarding the mechanisms by which the intervention might work. Via the CMO configuration and the formulation of patterns (demiregularities), the initial program theory is iteratively refined. ${ }^{20,21}$ The outcome is a program theory that is connected to the empirical data yet sufficiently abstracted from it to allow for generalizations regarding what works, for whom, and under what circumstances. Table 1 provides definitions of RS terms and other terms used in this article.

The present RS followed the 5 nonlinear and interrelated stages recommended by Pawson, as listed below. ${ }^{23}$ This article is presented according to the RAMESES reporting guidelines. ${ }^{24}$ Full details are available in our published protocol. ${ }^{25}$

\section{Stage 1. Focusing the Scope of the Realist Synthesis and Promoting Stakeholder Engagement}

The review team included academic researchers, decision makers, clinicians, frequent users of primary health care services, and research assistants from across Canada. To promote their engagement, all team members were invited to 2 working sessions, during which we focused the scope of the RS. Specifically, the review team identified the research question, clarified the purpose of the review, and articulated an initial program theory based on the findings of the parent systematic review ${ }^{26}$ and other CM literature. The initial program theory consisted of the following 5 main resources: case finding, care planning, coordination/ integration of services, self-management support, and 
intensity of the intervention (Supplemental Figure 1, http://www.AnnFamMed.org/content/18/3/218/suppl/ DC1). ${ }^{13-15,19}$ The working sessions also included a 3-hour training on the RS approach.
Stage 4. Extracting the Data

The extracted data were (1) bibliographic information, (2) study characteristics (location, setting, and design, definition of frequent users; population characteristics;

\section{Stage 2. Searching for Evidence} As planned in our protocol, ${ }_{1}^{25}$ we searched for evidence from all of the studies included in our parent systematic review detailing the methods and characteristics of the included studies. ${ }^{26}$ The comprehensive search strategy used in our parent systematic review yielded 21 peer-reviewed articles published during the period 1996 to September 2017 and evaluating 19 interventions in primary care settings designed to improve care among adult frequent users of health care services who were affected by at least 1 chronic physical condition. In accordance with RS methodology supporting the inclusion of data from various sources, we used a cluster search to identify additional documents relevant to each CM intervention. We emailed the 21 corresponding authors to request unpublished material and searched the associated academic and gray literature, which led to an additional set of 128 documents.

\section{Stage 3. Appraising the Quality} of Evidence

Per RS methodology, ${ }^{20,21}$ we appraised all of the selected peer-reviewed articles $(n=21)$ and documents from the gray literature $(n=128)$ for relevance (ie, contribution of the data to theory building/testing) and robustness (ie, credibility and trustworthiness of the data). ${ }^{20}$ On the basis of these criteria, we retained the 21 peerreviewed articles and 89 of the additional documents, evaluating a total of $19 \mathrm{CM}$ interventions (Figure 1).

\section{Figure 1. Study selection process.}

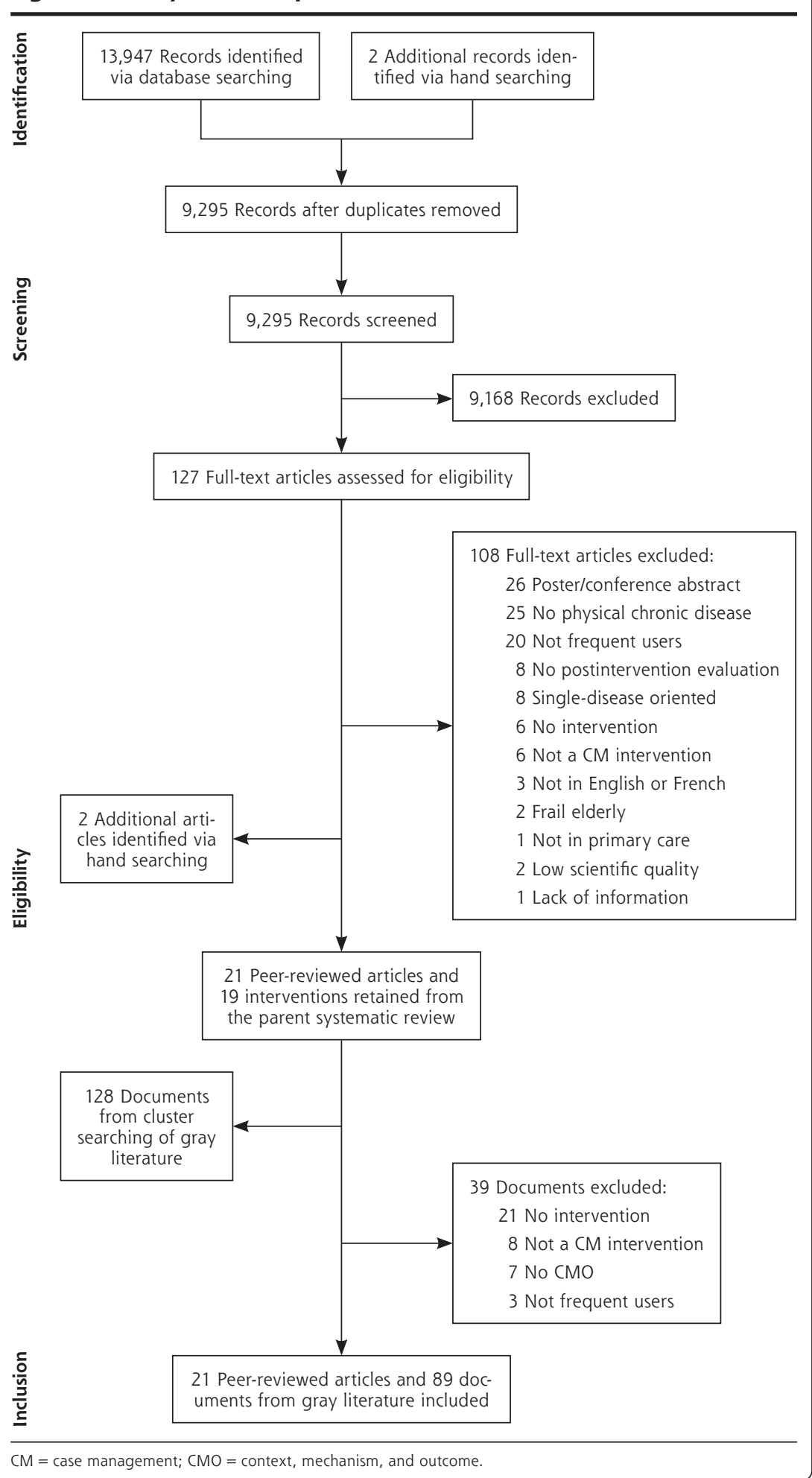


sample size; type, objective, frequency, and content of the intervention; length of the intervention sessions with patients; duration of follow-up; case-finding process $_{i}$ clinicians involved $_{i}$ intervention offered to the control group; data analysis; outcome characteristics and assessment instruments; and the intervention's effectiveness based on reported outcomes) (details of these findings are reported in the parent systematic review ${ }^{26}$ ), and (3) data related to the $\mathrm{CMO}$ configurations.

Four team members (M.C.C., M.L., O.C., F.F.) were involved in development of $\mathrm{CMO}$ configurations. For each intervention, they used an extraction table to systematically extract the relevant data (contexts, mechanisms, outcomes, and associated excerpts) from the included documents. Only CMOs that were clearly reported by the authors were extracted. Outcomes were used as starting points for building $\mathrm{CMO}$ configurations. Team members worked together on the first 5 interventions, which served as a learning exercise and to establish common processes and standards. Subsequently, they worked independently, creating data extraction tables of the $\mathrm{CMO}$ configurations for each of the 14 remaining interventions. A second team member repeated the process for each intervention, identifying additional $\mathrm{CMO}$ configurations. The $\mathrm{CMO}$ tables were then circulated to other team members (C.H., M.C.C., M.L., P.L.B., V.S., P.P.), who identified points of agreement and disagreement that were resolved via discussion and consensus. Once all CMO configurations of the interventions had been extracted, all data extraction tables were transferred to NVivo qualitative data analysis software (version 11; QSR International) and synthesized into $\mathrm{CMO}$ configurations that were used to refine the initial program theory.

\section{Stage 5. Synthesizing the Evidence}

To inform and modify the initial program theory, an abductive reasoning approach (in which there is an iterative back and forth between the theory and the data) was used. ${ }^{27}$ The CMOs were analyzed and demiregularities (patterns) identified. ${ }^{27}$ Regular discussions with the entire team helped to refine the initial program theory and to identify ways in which it was informed by the data. The iterative process of modification and refinement of the initial theory led to a refined program theory explaining how and why CM works.

\section{RESULTS}

\section{Description of the Included Studies}

The 19 included CM interventions were evaluated using quantitative methods $(\mathrm{n}=16)$ and mixed methods $(\mathrm{n}=3) .{ }^{26}$ Thirteen were conducted in the United States and 6 in other countries (Sweden, Canada, Switzerland, Australia, New Zealand, and the United Kingdom). The studies included 17 to 14,140 participants, with an average age range of 20 to 66 years. The proportion of women varied from $25 \%$ to $77 \%$.

\section{CMO Configurations and Demiregularities}

Eleven CMO configurations were developed (Table

2). They suggested that $C M$ might yield 7 possible positive outcomes (improvements of self-management skills, patient adherence to treatment and recommendations, patient satisfaction, health status, quality of life, and quality of care, and reductions in health care use and costs) when the following mechanisms are triggered: (a) patients feel supported, respected, and

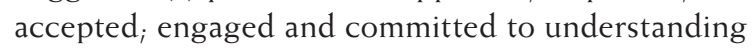
the care plan and how to access relevant health care services; feel their concerns are heard; are less anxious and more secure; and are more empowered to selfmanage $_{i}$ (b) clinicians feel supported and have a deeper understanding of the patient's situation. The ability of each mechanism to trigger a positive outcome was dependent on the context of the intervention, providing patients with easy access to a trusted case manager who provides comprehensive care while maintaining positive interactions with patients. Two demiregularities were identified, as described below.

\section{Demiregularity 1. Developing a Trusting Patient-Clinician Relationship}

The relationship developed between the patient and an experienced and trusted case manager appeared to play a key role in the effectiveness of CM for frequent users. ${ }^{28-33}$ This relationship influences a patient's motivation to engage in their care (CMOs 2, 3, \& 9). Patients' past experiences can affect the interactions they have with clinicians (CMO 3). ${ }^{28-32,34} \mathrm{~A}$ meaningful relationship is built on trust $\mathrm{t}^{28-32}$ and is essential for empowering patients to self-manage their care, ${ }^{28,30-32}$ as noted by Grinberg et $\mathrm{a}^{28}$ in their evaluation of the Camden Coalition of Healthcare Providers, a multidisciplinary CM program for complex frequent users of inpatient service:

"Participants often drew a connection between this relationship and active motivation. (...) [They] also described genuineness as a key ingredient of their relationship with the members of their Coalition care teams: I loved working with her. I'll work with her any day of the week, she was normal to $\mathrm{me}_{\text {; }}$ she talked to me as a person, not as a patient. This genuineness in patient interactions was often cited as a catalyst for personal change: [knowing that the care team was] interested in me...it's like wow, me? I felt good, I felt better, I felt somebody really cares about me. I'm living, and I'm not here by myself. And I think that what's made me, you know, 
Table 2. CMO Configurations

\begin{tabular}{|c|c|c|}
\hline Theme & CMO Configuration & Evidence (References) \\
\hline $\begin{array}{l}\text { Coordination } \\
\text { and health } \\
\text { navigation }\end{array}$ & $\begin{array}{l}\text { If frequent users are directed through the health care system and are enabled to con- } \\
\text { nect with clinicians and community services working in close collaboration (C), they } \\
\text { have a better understanding of how to access and obtain relevant health care services } \\
\text { in appropriate settings. Their knowledge and ability to navigate within the health care } \\
\text { system and to communicate with clinicians are strengthened, and they become more } \\
\text { engaged in their care (M). This improves their self-management skills and health sta- } \\
\text { tus and reduces health care use and costs (O). (CMO 1) }\end{array}$ & 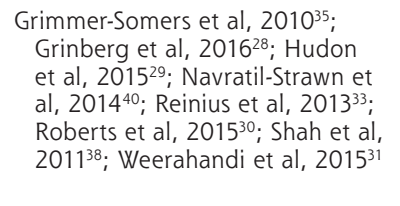 \\
\hline \multirow[t]{2}{*}{$\begin{array}{l}\text { Patient and } \\
\text { health care } \\
\text { clinician } \\
\text { relationship }\end{array}$} & $\begin{array}{l}\text { If case managers are able to develop trusting relationships with frequent users (C), } \\
\text { frequent users trust them, feel safe, and develop meaningful relationships with them. } \\
\text { This meaningful relationship motivates patients to be engaged in their care (M). In } \\
\text { turn, their self-management skills improve, their health condition(s) stabilizes, and } \\
\text { health care use and costs are reduced (O). (CMO 2) }\end{array}$ & $\begin{array}{l}\text { Crane et al, 201232; Grinberg et } \\
\text { al, 2016 } \\
\text { Roberts et al, 2015 } 30 \text {; Weerahandi } \\
\text { et al, } 2015^{31}\end{array}$ \\
\hline & $\begin{array}{l}\text { If frequent users have a negative interaction with case managers, feel disrespected, } \\
\text { discriminated against, or not connected with them }(C) \text {, frequent users feel upset, dis- } \\
\text { satisfied, and frustrated with their encounter. They are unable to develop a trusting } \\
\text { relationship with their case managers and are not willing to engage in their care (M). } \\
\text { This limits the development of their self-management skills, does not improve their } \\
\text { quality of life, and does not change health care use and costs (O). (CMO 3) }\end{array}$ & $\begin{array}{l}\text { Grinberg et al, 201628; Sledge et } \\
\text { al, } 2006^{34}\end{array}$ \\
\hline \multirow[t]{3}{*}{$\begin{array}{l}\text { Patient and } \\
\text { health care } \\
\text { clinician } \\
\text { engage- } \\
\text { ment }\end{array}$} & $\begin{array}{l}\text { If case managers are flexible, able to adapt, and open to change their approach by } \\
\text { involving frequent users in their care planning }(C) \text {, frequent users tend to accept the } \\
\text { CM program, tend to understand their role in it, and are willing to engage in their } \\
\text { care (M). This improves their self-management skills, health status, and quality of care } \\
\text { and reduces health care use and costs (O). (CMO 4) }\end{array}$ & 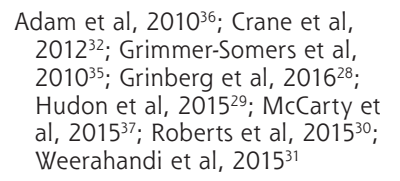 \\
\hline & $\begin{array}{l}\text { If case managers are willing to be engaged and committed to the program and to take } \\
\text { an active role in care planning (C), frequent users accept the program, perceive it to } \\
\text { be beneficial, and become more engaged in their health care (M), which improves } \\
\text { their self-management skills and reduces health care use (O). (CMO 5) }\end{array}$ & $\begin{array}{l}\text { Adam et al, } 2010^{36} \text {; Grinberg et } \\
\text { al, 2016 } \\
\text { McCarty et al, } 2015^{37} ; \text { Pope et } \\
\text { al, 2000 } \\
\text { Weerahandi et al, } 2015^{31}\end{array}$ \\
\hline & $\begin{array}{l}\text { If frequent users are not involved in their care planning }(\mathrm{C}) \text {, they do not feel engaged } \\
\text { and will deviate from their care plan because they do not understand it or do not } \\
\text { agree with it (M). Consequently, they will continue to frequently and inappropriately } \\
\text { use health care services (O). (CMO 6) }\end{array}$ & $\begin{array}{l}\text { Adam et al, } 2010^{36} \text {; Bodenmann et } \\
\text { al, 2017 }{ }^{39} \text {; Pope et al, } 2000^{42}\end{array}$ \\
\hline \multirow[t]{3}{*}{$\begin{array}{l}\text { Patient and } \\
\text { health care } \\
\text { clinician } \\
\text { support }\end{array}$} & $\begin{array}{l}\text { If a comprehensive and holistic approach addressing both medical and social issues is } \\
\text { provided to frequent users (C), they feel their concerns are heard and their needs are } \\
\text { taken seriously. They feel supported and satisfied with the care received and moti- } \\
\text { vated to be engaged in their care (M). This improves their self-management skills and } \\
\text { health status and reduces health care use (O). (CMO 8) }\end{array}$ & $\begin{array}{l}\text { Brown et al, 200541; Grimmer- } \\
\text { Somers et al, 2010 } \\
2015^{29} \text {; Pope et } \text { : Hudon et al, } 2000^{42} \text {; Shah } \\
\text { et al, } 2011^{38}\end{array}$ \\
\hline & $\begin{array}{l}\text { If frequent users have easy access to case managers who provide regular follow-up } \\
\text { meetings (C), frequent users feel supported and cared for in the management of } \\
\text { their health issues and trusted by their case managers (M). This improves their self- } \\
\text { management skills, health status, and quality of life and reduces health care use and } \\
\text { costs (O). (CMO 9) }\end{array}$ & 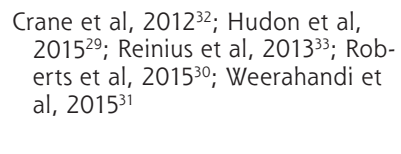 \\
\hline & $\begin{array}{l}\text { If clinicians who are overwhelmed by the complex needs of frequent users in an over- } \\
\text { loaded health care system work in collaboration with an interdisciplinary team }(C) \text {, } \\
\text { they feel supported by the members of the team and satisfied with the program and } \\
\text { are willing to engage in the CM program (M). This improves the quality of care they } \\
\text { provide to frequent users and reduces patients' health care use (O). (CMO 10) }\end{array}$ & $\begin{array}{l}\text { Adam et al, 2010 } 36 \text {; Brown et al, } \\
2005^{41} \text {; McCarty et al, } 2015^{37}\end{array}$ \\
\hline $\begin{array}{l}\text { Self-man- } \\
\text { agement } \\
\text { support }\end{array}$ & $\begin{array}{l}\text { If frequent users are involved in their care planning and receive self-management sup- } \\
\text { port }(\mathrm{C}) \text {, they develop a greater understanding of their condition, are motivated to } \\
\text { take an active role in their care, and feel confident in their ability to obtain medical } \\
\text { and social resources (M). This improves their self-management skills, health status, and } \\
\text { quality of life and reduces health care use (O). (CMO 11) }\end{array}$ & 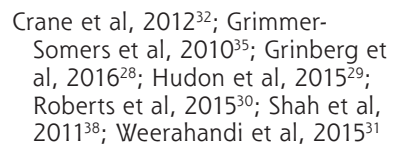 \\
\hline
\end{tabular}

actually do it. I started takin' my medication, I started, you know, getting out." (p. 250)

Aptitudes and skills of clinicians influence the extent to which patients are engaged in their care $(\mathrm{CMO}$ 2). ${ }^{28,30-32,35}$ The ability of case managers to develop positive relationships with their patients fosters mutual trust, which in turn motivates both patient and clinician to engage in the $\mathrm{CM}$ intervention. ${ }^{28,30-32} \mathrm{~A}$ calm, confident, sensitive, friendly, empathetic, and supportive case manager inspires patients' confidence, increasing their likelihood to be engaged in their care. ${ }^{28,30-32}$ Because they work with patients with complex care needs, case managers should take time to listen to 
them, understand their situation, and be accepting of them. ${ }^{29,30}$ Regular follow-up meetings with the same clinician contribute to the development of a trusting relationship (CMO 9), ${ }_{1}^{29-33}$ and patients are more likely to feel secure, be honest, and to be engaged in their care. ${ }^{28,31}$ Patients who are able to self-manage their conditions experience fewer health complications. Thus, our analysis suggests the importance of this demiregularity in reducing inappropriate use of health care services ${ }^{28,31,32}$ and thereby related costs. ${ }^{28,32}$ In an evaluation of an intensive CM program for frequent users of inpatient services, with chronic conditions and complex care needs, Roberts et $\mathrm{al}^{30}$ found the following:

"Key to the success of the work of the CCL [case manager] is the ability to establish trusting relationships with patients, their families, and other caregivers. Many of the high utilizers of Safety-Net hospitals live not only with the challenges surrounding multiple chronic diseases but also with poverty, mental illness, and chaotic life circumstances. The CCLs must understand the context of the lives of their patients and accept those individuals where they are. It is crucial to the CCL's success that we hire those with an aptitude for ongoing professional development regarding effective interactions with patients and dealing with their barriers to selfmanagement." (p. 259)

\section{Demiregularity 2. Engaging Patients and Clinicians in Case Management Interventions}

Involving patients in the development of their care plan by considering needs, prioritizing what they want to address, reaching an agreement on care recommendations, explaining their role in their own care, or encouraging them to make their own health-related decisions helps ensure that the patients feel engaged in their care and self-manage their conditions (CMOs 4, 6, and 11). ${ }^{28-31,35-37}$ This requires that case managers be open to this process ${ }^{30,31,35}$ and to providing self-management support. ${ }^{28-32,35,38}$ In addition, educating patients on health condition(s) helps improve understanding of health issues, which in turn increases confidence in the ability to self-manage, ${ }_{1}^{28-30,35,38}$ improves health status, ${ }_{1}^{31}$ and decreases health care service use..$^{31,32,38}$

The provision of easy access to and assistance with health care services, particularly navigation services, improves patients' ability to seek and reach appropriate care when needed (CMO 1) $)^{30,33,35,39,40}$ and helps sustain their engagement in their care. This prevents inappropriate use of health care services. ${ }^{39,40}$ Considering that patients' medical and social issues might also influence their engagement, such a comprehensive approach helps patients feel that they are taken seriously, respected, well cared for, satisfied, and motivated to be engaged in their care. $29,35,38,41,42$ Hence, they become actively involved in their care and improve their self-management skills. ${ }^{29,35,38}$ Again, this can lead to a decrease in inappropriate health care service use. . $^{38,41,42}$

The engagement of case managers and clinicians in the $\mathrm{CM}$ interventions is also important (CMOs 5, 7, and 10$)^{28,31,36,37,41-44}$ because it helps improve patients' self-management skills ${ }^{28}$ and reduces inappropriate health care use and costs. ${ }^{28,31,36,37,42-44}$ Case managers who are committed to the intervention and take an active role in caring for patients have a positive influence on patients' motivation to engage in their care. ${ }^{28,31,36,37,42-44}$ As Green et $\mathrm{a}^{45}$ reported,

"Clients have described the motivation they feel to adhere to treatment regimens when they know there are healthcare providers taking an active role in caring for them. The clients engage with the team and become active partners in their own health care." (p. 5)

The 2 demiregularities are intrinsically linked; a trusting patient-clinician relationship is a key element of success for meaningful partnerships and patient engagement. It is necessary for the clinician to gain the patient's trust and to maintain a relationship in which the patient feels engaged in their care, thus triggering mechanisms that generate positive outcomes.

With regard to frequent users with substance use disorders, clinicians' compliance with their care plan is crucial. ${ }^{42,44}$ When clinicians do not respect the recommendation of restriction of opioids, frequent users with substance abuse issues tend to use health care services to obtain opioids.

\section{Refined Program Theory Regarding How Case Management Works in Primary Care for Frequent Users With Chronic Conditions} Refinement of our initial theory consisted, for the most part, of further articulating the mechanisms because our initial theory focused more on CM resources. The refined program theory suggests 4 resources (care planning, coordination and health care navigation, selfmanagement support, and support for clinicians) and includes the mechanisms (central arrow, Figure 2) that connect contexts and outcomes of CM for frequent users of health care services with chronic conditions.

\section{DISCUSSION}

Our refined program theory of CM proposes that in the context of easy access to an experienced and trusted case manager who provides comprehensive care while maintaining positive interactions with patients, the development of a trusting relationship between the patient and the clinician fosters the engagement of both when the following mechanisms are triggered: (a) 
patients feel supported, respected, and accepted ${ }_{i}$ are engaged and committed to understanding their care plan and how to access relevant health care services; feel their concerns are heard ${ }_{i}$ are less anxious and more secure, and are empowered to self-manage, and (b) clinicians feel supported and have a deeper understanding of the patient's situation. These relationships provide a causal explanation for the success of CM interventions in improving patient and clinician experiences and overall health outcomes and decreasing health system costs (outcomes) (Figure 2).

In a study of intensive outpatient care programs for patients with complex care needs, $\mathrm{O}^{\prime}$ Brien et $\mathrm{al}^{46}$ interviewed clinicians and program leaders and found that patient-clinician relationships built on trust are critical for developing care coordination and treatment plans and these relationships influence patients' engagement in care. With respect to the present RS, we were able to elucidate on the trusting relationship and provide detail regarding this mechanism (central arrow, Figure 2). This detail is an important contribution that can provide clinicians with guidance for exhibiting behavior that can help to build trust with their patients.
These results corroborate those of Elliott et $\mathrm{al}_{1}{ }^{47}$ who used RS to understand the engagement of older adults in health care decision making. Like us, those authors found that developing trust between the patient and the clinician can help the patient feel engaged in decision making.

\section{Contribution to Research, Clinical Practice, and Policy}

Our program theory looks beyond program resources and determination of success and exposes the mechanisms that CM triggers in patients and clinicians in various contexts that generate positive outcomes. It will help clinicians identify essential elements of CM to incorporate into their daily practice. Regarding patients, our program theory might help them recognize the important role they play by engaging in their care planning. Using this theory to frame CM work with patients might be beneficial (and in turn, might help to refine the theory) in clinical settings and might help policy makers design, plan, and implement effective CM programs in their jurisdictions.

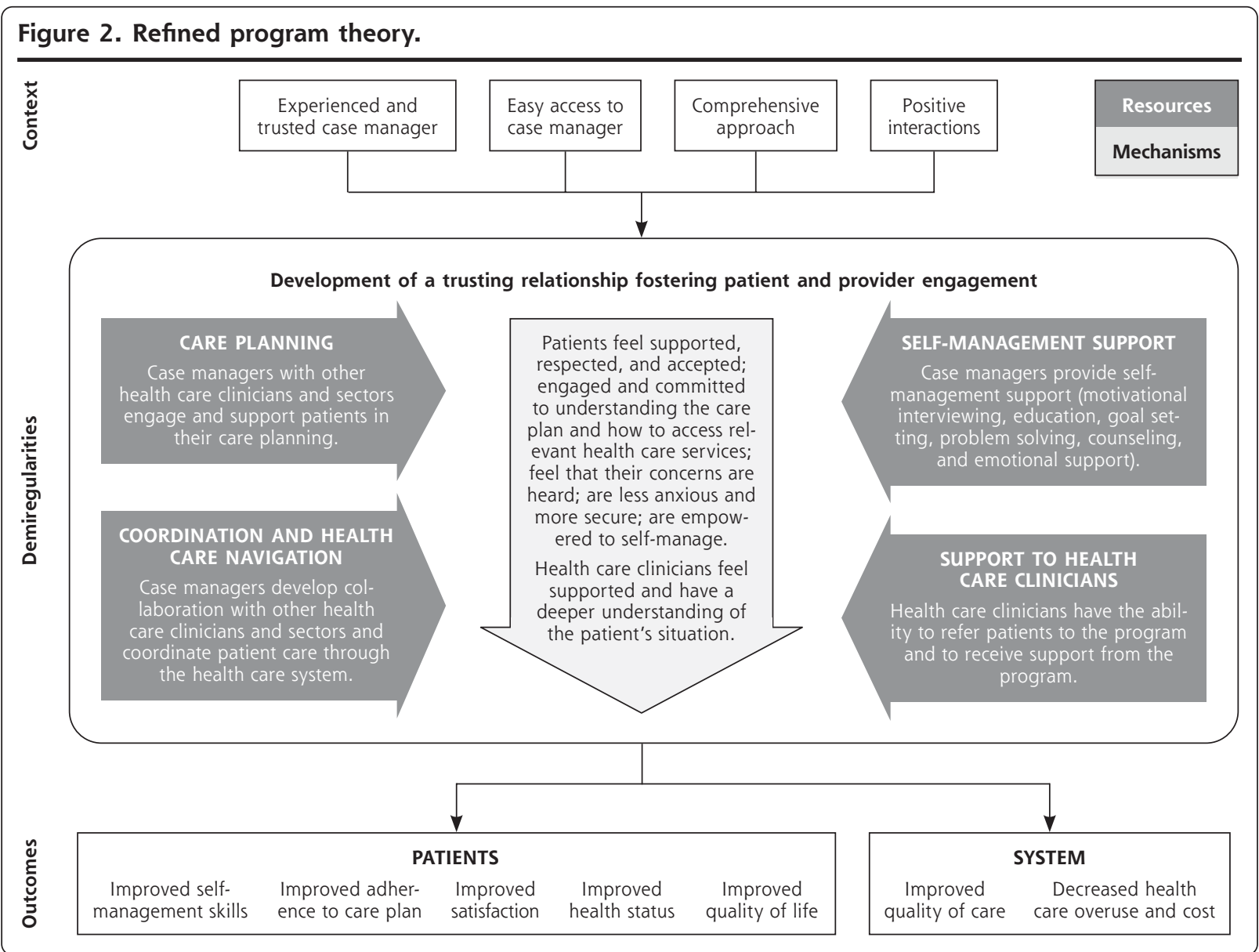

ANNALS OF FAMILY MEDICINE + WWW.ANNFAMMED.ORG + VOL. 18, NO. 3 + MAY/JUNE 2020 


\section{Strengths and Limitations}

Given that CM stakeholders, including patients who are frequent users of health care services, were members of the review team, we are confident that this work is anchored not only in the empirical literature but also in the practical experience of CM stakeholders across Canada. However, although we included all published material regarding the $\mathrm{CM}$ interventions, our present results should be critically interpreted in light of the limited descriptions available regarding the $\mathrm{CM}$ interventions and how individuals reacted to them. Further research is required to examine if the professional role of the case manager (nurse, social worker, other) or the setting of the CM (clinic, community, home) might have an influence on the development of the relationship. Our theory of CM pertains to frequent users of health care services with chronic conditions. The knowledge base could be improved by testing our theory via realist evaluation of CM in real context. ${ }^{48}$

\section{CONCLUSIONS}

With the present RS, we were able to refine what is known about contextual factors of CM in primary care for frequent users with chronic conditions that lead to positive patient and system-level outcomes and to uncover the mechanisms these factors need to trigger to generate the desired outcomes. We propose a program theory that the objective of CM should be to enable an experienced and accessible case manager, a comprehensive approach to patient care, and positive interactions throughout the health care process. This will trigger the development of a trusting relationship that fosters both patient and clinician engagement and will lead to improved patient and clinician experiences, better patient health outcomes, and decreased health care system costs.

To read or post commentaries in response to this article, see it online at http://www.AnnFamMed.org/content/18/3/218.

Submitted April 5, 2019; submitted, revised, July 29, 2019; accepted September 6, 2019.

Key words: case management; frequent users; chronic conditions; realist synthesis; program theory; CMO configurations; causal mechanisms; primary care issues

Author affiliations: Département de Médecine de Famille et de Médecine d'Urgence, Université de Sherbrooke, Sherbrooke, Québec, Canada (C.H.); Département des Sciences de la Santé, Université du Québec à Chicoutimi, Saguenay, Québec, Canada, (M.C.C.); Memorial University, Primary Healthcare Research Unit, St. John's, Newfoundland and Labrador, Canada (K.A.B., O.C.); Department of Community Health and Epidemiology, University of Saskatchewan, Saskatoon, Saskatchewan, Canada (N.M.); Dalhousie University, Department of Family Medicine, Halifax, Nova Scotia, Canada (F.B.); Département de Médecine de Famille, Université McGill, Montréal, Québec, Canada (P.L.B., P.P.); Faculté de Médecine et des Sciences de la Santé, Université de Sherbrooke, Longueuil, Québec, Canada (A.D.); Department of Academic Family Medicine, University of
Saskatchewan, Saskatoon, Saskatchewan, Canada (V.R.R.); Département de Médecine Familiale et de Médecine d'Urgence, Université Laval, Québec, Québec, Canada (F.L.); Faculté de Pharmacie, Université Laval, Québec, Québec, Canada (L.G.); École de Travail Social, Université de Sherbrooke, Sherbrooke, Québec, Canada (P.M.); Centre Intégré Universitaire de Santé et de Services Sociaux du Saguenay-Lac-Saint-Jean, Saguenay, Québec, Canada (M.L.); Department of Psychology, University of Saskatchewan, Saskatoon, Saskatchewan, Canada (F.F.); Quebec-SPOR SUPPORT Unit, Québec, Québec, Canada (V.S.); Newfoundland and Labrador-SPOR SUPPORT Unit, Saint John's Newfoundland and Labrador, Canada (M.W.)

Author contributions: C.H., M.C.C., K.A.B., N.M., and F.B. conceived the review and participated in its design and coordination; P.B. and P.P. guided the methodologic steps of the realist synthesis; M.C.C., M.L., F.F., and O.C. conducted the data collection and analysis; all authors participated in the data synthesis; M.L. and P.B. drafted the manuscript under the guidance of C.H. and M.C.C.; all authors were involved in drafting and revising the manuscript.

Funding support: This project was funded by the Pan-Canadian SPOR Network in Primary and Integrated Health Care Innovations-Knowledge Synthesis Grant of the Canadian Institutes of Health Research, with contributions from the Department of Family and Emergency Medicine of the University of Sherbrooke, the University of Sherbrooke Hospital Centre, Réseau 1 Québec, the Institut Universitaire de Première Ligne en Santé et Services of the Integrated University Health and Social Services Centre of L'Estrie-CHUS, the University of Québec in Chicoutimi, the Newfoundland and Labrador Medical Association, and the Saskatchewan Health Research Foundation.

Acknowledgments: We would like to thank our participating decision makers (Antoine Groulx, Martine Couture, Cameron Campbell, Margaret Baker, Lynn Edwards, Tara Sampalli), patient partners (Claude Spence, Gilles Gauthier), and clinicians (Julie Godbout, Breanna Davis, Norma Rabbitskin) for their contribution to this project.

Supplementary materials: Available at http://www.AnnFamMed. org/content/18/3/218/suppl/DC1/.

\section{References}

1. Bodenheimer T, Berry-Millett R. Follow the money--controlling expenditures by improving care for patients needing costly services. N Engl J Med. 2009;361(16):1521-1523.

2. LaCalle $E$, Rabin E. Frequent users of emergency departments: the myths, the data, and the policy implications. Ann Emerg Med. 2010; 56(1):42-48

3. Wodchis WP. High cost users: driving value with a patient-centred health system. https://www.ryerson.ca/content/dam/crncc/knowledge/ eventsandpresentations/integratedcare/healthconnections/Walter\%20 Wodchis.pdf. Published Jun 30, 2013. Accessed Apr 20, 2020.

4. Schoen C, Osborn R, Squires D, Doty M, Pierson R, Applebaum S. New 2011 survey of patients with complex care needs in eleven countries finds that care is often poorly coordinated. Health Aff (Millwood). 2011;30(12):2437-2448.

5. Sun $B C$, Burstin HR, Brennan TA. Predictors and outcomes of frequent emergency department users. Acad Emerg Med. 2003;10(4):320-328.

6. Doupe MB, Palatnick W, Day S, et al. Frequent users of emergency departments: developing standard definitions and defining prominent risk factors. Ann Emerg Med. 2012;60(1):24-32.

7. Sandoval E, Smith S, Walter J, et al. A comparison of frequent and infrequent visitors to an urban emergency department. J Emerg Med. 2010;38(2):115-121.

8. Byrne M, Murphy AW, Plunkett PK, McGee HM, Murray A, Bury G. Frequent attenders to an emergency department: a study of primary health care use, medical profile, and psychosocial characteristics. Ann Emerg Med. 2003;41(3):309-318. 
9. Mandelberg JH, Kuhn RE, Kohn MA. Epidemiologic analysis of an urban, public emergency department's frequent users. Acad Emerg Med. 2000;7(6):637-646.

10. Kersnik J, Svab I, Vegnuti M. Frequent attenders in general practice: quality of life, patient satisfaction, use of medical services and GP characteristics. Scand J Prim Health Care. 2001;19(3):174-177.

11. Fuda KK, Immekus R. Frequent users of Massachusetts emergency departments: a statewide analysis. Ann Emerg Med. 2006;48(1):9-16.

12. Hansagi H, Allebeck P, Edhag O, Magnusson G. Frequency of emergency department attendances as a predictor of mortality: nineyear follow-up of a population-based cohort. J Public Health Med. 1990;12(1):39-44.

13. Althaus F, Paroz S, Hugli O, et al. Effectiveness of interventions targeting frequent users of emergency departments: a systematic review. Ann Emerg Med. 2011;58(1):41-52.e42.

14. Kumar GS, Klein R. Effectiveness of case management strategies in reducing emergency department visits in frequent user patient populations: a systematic review. J Emerg Med. 2013;44(3):717-729.

15. Soril LJ, Leggett LE, Lorenzetti DL, Noseworthy TW, Clement FM. Reducing frequent visits to the emergency department: a systematic review of interventions. PLoS One. 2015;10(4):e0123660.

16. Case Management Society of America. What is a case manager? https://www.cmsa.org/who-we-are/what-is-a-case-manager/. Published Jun 9, 2017. Accessed Feb 26, 2020.

17. Bodenheimer TS, Berry-Millett R. Care management of patients with complex health care needs. Robert Wood Johnson Foundation, The Synthesis Project. https://www.rwjf.org/en/library/research/2009/12/ care-management-of-patients-with-complex-health-care-needs.html. Published Dec 1, 2009. Accessed Feb 26, 2020.

18. Center for Health Care Strategies. Care management definition and framework. https://www.chcs.org/media/Care_Management_ Framework.pdf. Published 2007. Accessed Feb 26, 2020.

19. Raven MC, Kushel M, Ko MJ, Penko J, Bindman AB. The effectiveness of emergency department visit reduction programs: a systematic review. Ann Emerg Med. 2016;68(4):467-483.e15.

20. Pawson R, Greenhalgh T, Harvey G, Walshe K. Realist synthesis: an introduction. RMP Methods Paper. ESRC Research Methods Programme, University of Manchester. 10.1177/1356389017746718. Published Feb 2004. Accessed Feb 26, 2020.

21. Pawson R, Tilley N. Realistic Evaluation. London, UK: Sage Publications; 1997.

22. Dalkin SM, Greenhalgh J, Jones D, Cunningham B, Lhussier M. What's in a mechanism? Development of a key concept in realist evaluation. Implement Sci. 2015;10:49.

23. Pawson R. Evidence-Based Policy: A Realist Perspective. London, UK: Sage Publications; 2006.

24. Wong G, Greenhalgh T, Westhorp G, Buckingham J, Pawson R. RAMESES publication standards: realist syntheses. J Adv Nurs. 2013; 69(5):1005-1022.

25. Hudon C, Chouinard MC, Aubrey-Bassler K, et al. Case management in primary care among frequent users of healthcare services with chronic conditions: protocol of a realist synthesis. BMJ Open. 2017; 7(9):e017701.

26. Hudon C, Chouinard MC, Pluye $P$, et al. Characteristics of case management in primary care associated with positive outcomes for frequent users of health care: a systematic review. Ann Fam Med. 2019;17(5):448-458.

27. Robert $E$, Ridde V. L'approche réaliste pour l'évaluation de programmes et la revue systématique: de la théorie à la pratique. Mesure et Évaluation en Éducation. 2013;36(3):79-108. [In French]

28. Grinberg C, Hawthorne M, LaNoue M, Brenner J, Mautner D. The core of care management: the role of authentic relationships in caring for patients with frequent hospitalizations. Popul Health Manag. 2016;19(4):248-256.

29. Hudon C, Chouinard MC, Diadiou F, Lambert M, Bouliane D. Case management in primary care for frequent users of health care services with chronic diseases: a qualitative study of patient and family experience. Ann Fam Med. 2015;13(6):523-528.
30. Roberts SR, Crigler J, Ramirez C, Sisco D, Early GL. Working with socially and medically complex patients: when care transitions are circular, overlapping, and continual rather than linear and finite. J Healthe Qual. 2015;37(4):245-265.

31. Weerahandi $H$, Basso Lipani M, Kalman J, et al. Effects of a psychosocial transitional care model on hospitalizations and cost of care for high utilizers. Soc Work Health Care. 2015;54(6):485-498.

32. Crane S, Collins L, Hall J, Rochester D, Patch S. Reducing utilization by uninsured frequent users of the emergency department: combining case management and drop-in group medical appointments. J Am Board Fam Med. 2012;25(2):184-191.

33. Reinius $P$, Johansson $M$, Fjellner $A$, Werr J, Ohlén $G$, Edgren $G$. A telephone-based case-management intervention reduces healthcare utilization for frequent emergency department visitors. Eur J Emerg Med. 2013;20(5):327-334.

34. Sledge $W H$, Brown KE, Levine JM, et al. A randomized trial of primary intensive care to reduce hospital admissions in patients with high utilization of inpatient services. Dis Manag. 2006;9(6):328-338.

35. Grimmer-Somers K, Johnston K, Somers E, Luker J, Alemao LA, Jones $D$. A holistic client-centred program for vulnerable frequent hospital attenders: cost efficiencies and changed practices. Aust N Z J Public Health. 2010;34(6):609-612.

36. Adam P, Brandenburg DL, Bremer KL, Nordstrom DL. Effects of team care of frequent attenders on patients and physicians. Fam Syst Health. 2010;28(3):247-257.

37. McCarty RL, Zarn J, Fenn R, Collins RD. Frequent ED utilizers: a case management program to address patient needs. Nurs Manage. 2015, 46(9):24-31.

38. Shah R, Chen C, O'Rourke S, Lee M, Mohanty SA, Abraham J. Evaluation of care management for the uninsured. Med Care. 2011; 49(2):166-171.

39. Bodenmann P, Velonaki VS, Griffin JL, et al. Case management may reduce emergency department frequent use in a universal health coverage system: a randomized controlled trial. J Gen Intern Med. 2017;32(5):508-515.

40. Navratil-Strawn JL, Hawkins K, Wells TS, et al. An emergency room decision-support program that increased physician office visits, decreased emergency room visits, and saved money. Popul Health Manag. 2014;17(5):257-264.

41. Brown KE, Levine JM, Fiellin DA, O'Connor P, Sledge WH. Primary intensive care: pilot study of a primary care-based intervention for high-utilizing patients. Dis Manag. 2005;8(3):169-177.

42. Pope D, Fernandes CM, Bouthillette F, Etherington J. Frequent users of the emergency department: a program to improve care and reduce visits. CMAJ. 2000;162(7):1017-1020.

43. Skinner J, Carter L, Haxton C. Case management of patients who frequently present to a Scottish emergency department. Emerg Med J. 2009;26(2):103-105.

44. Grover CA, Close RJ, Villarreal K, Goldman LM. Emergency department frequent user: pilot study of intensive case management to reduce visits and computed tomography. West J Emerg Med. 2010; 11(4):336-343.

45. Green SR, Singh V, O'Byrne W. Hope for New Jersey's city hospitals: the Camden Initiative. Perspect Health Inf Manag. 2010;7:1d.

46. O'Brien CW, Breland JY, Slightam C, Nevedal A, Zulman DM. Engaging high-risk patients in intensive care coordination programs: the engagement through CARInG framework. Transl Behav Med. 2018;8(3):351-356.

47. Elliott J, McNeil H, Ashbourne J, Huson K, Boscart V, Stolee P. Engaging older adults in health care decision-making: a realist synthesis. Patient. 2016;9(5):383-393.

48. Hudon C, Chouinard MC, Aubrey-Bassler K, et al. Case management in primary care for frequent users of healthcare services with chronic diseases and complex care needs: an implementation and realist evaluation protocol. BMJ Open. 2018;8(11):e026433. 